\title{
La construcción del paisaje en la literatura de viajes en Honduras durante los siglos XIX y XX
}

Wendy Cálix ${ }^{1}$

Norma Lara ${ }^{2}$

\section{RESUMEN}

El estudio de la literatura de viajes como un género literario posibilita acercarse a la temporalidad de los hechos descritos o narrados por diversos viajeros, que en este caso visitaron Centroamérica; al respecto, principalmente interesan los textos en los que se relata su visita a Honduras, los cuales al recrearse permiten aproximarse al paisaje del país. Aldous Huxley, Harry A. Franck y Frank Vincent han dejado en sus libros publicados a finales del siglo XIX y principios del XX, un recuento de su viaje a tierras centroamericanas, es así que este estudio sobre la construcción del paisaje pretende indagar en los principales rasgos físicos distintivos que caracterizan a Honduras e identificar los elementos principales que se destacan en su paisaje natural, por medio de la descripción de los ambientes rurales y urbanos en los que se reconoce la configuración de los espacios naturales, las ciudades y el país.

En cuanto a la metodología de trabajo se empleó el enfoque cualitativo a partir del método de literatura comparada en los libros en estudio, junto a la investigación documental. Entre los resultados más destacados están las diversas descripciones encontradas sobre el paisaje natural, sobresale en los ambientes urbanos la herencia arquitectónica española desde los tiempos de la Colonia, relatos sobre las principales ciudades del país para esa época histórica, inferencias sobre los habitantes y la imagen de la ciudad; respecto a los ambientes rurales, se señala las referencias sobre la belleza natural del país y los abundantes bosques y ríos que rodean el territorio, es la representación de este paisaje la que nos invita a regresar a la Honduras de tiempos pasados.

1 Beneficiaria de una beca de estudiante de posgrado financiada por la DICYP, estudiante de la Maestría en Literatura Centroamericana, UNAH: wcalix2002@yahoo.es

2 Profesora universitaria asesora, Escuela de Letras, Facultad de Humanidades y Artes, UNAH: nlaraerazo@yahoo.com 
Palabras clave: literatura de viajes, construcción del paisaje, Honduras, Aldous Huxley, Harry Franck, Frank Vincent, siglo XIX, siglo XX.

\section{ABSTRACT}

The study of travel writing as a literary genre brings us to the timing of the events described and / or narrated by various travelers who visited Central America in this case, we were mainly interested in texts referred to his visit to Honduras, which allows us to approach and recreate the landscape of the country. Aldous Huxley, Harry A. Franck and Frank Vincent have published their books in the late nineteenth and early twentieth century recounting their trip to Central America, so, this study on landscape construction aims to investigate the main physical and distinctive traits that characterize Honduras, which are highlighted in the natural landscape. It is through the description of rural and urban environments that the configuration of natural areas, cities and country is recognized.

The qualitative approach was used as methodology, starting with the method of comparative literature in books the study of Documentary Research. Among the most important results that are found are the various descriptions on natural landscape, in urban environments the Spanish architectural heritage from colonial times seem to stand out, along with the stories of major cities from that historical era, the cities' images and the populations' inferences; in regards to the rural environment, references on the country's natural beauty and abundant forests and rivers surrounding the territory, represents the landscape that invites us to return to this particular time in Honduras history.

Words key: travel literature, landscape construction, cityscape, rural landscape, Honduras, nineteenth century, twentieth century. 


\section{INTRODUCCIÓN}

Dentro del caudal de investigaciones que fortalecen los estudios literarios, históricos y culturales se encuentra la investigación denominada "La construcción del paisaje en la literatura de viajes a finales del siglo XIX y principios del XX", la cual pretende acercarnos a la mirada de algunos viajeros que recorrieron nuestro país. Aldous Huxley, Harry Franck y Frank Vincent permanecieron en Honduras por un breve tiempo, pero en sus libros se narran los acontecimientos de su visita, principalmente se detalla aspectos sobre Honduras y su gente, ciudades, riquezas naturales y otros elementos.

El estudio de la literatura de viajes permite indagar en las esferas de la realidad que el texto mismo aporta, en este caso se desarrolla la temática relativa a la construcción del paisaje, de la cual nacen una serie de preguntas sobre cómo es la construcción del paisaje en la literatura de viaje y cuáles son los rasgos distintivos en la construcción del paisaje en la Honduras de finales del siglo XIX y principios del XX. Responder a estas preguntas permitirá enriquecer la visión de Honduras para ese momento histórico en particular y destacar los principales elementos del paisaje hondureño que son presentados en los textos de los autores antes mencionados.

Esta investigación pretende profundizar en la literatura de viajes, específicamente en el estudio sobre Honduras, destacándola como uno de los destinos de interés en una época histórica marcada por el auge comercial y los cambios políticos. El viajero por su misma condición es un descubridor de la realidad, haciendo un retrato de esta y, a su vez, realizando inferencias sobre ella. En consecuencia, el estudio sobre la construcción del paisaje es un aspecto que desde la mirada literaria e histórica permite regresar al pasado y determinar, sobre la base del presente, un redescubrimiento de Honduras para visualizar el registro literario como memoria histórica.

Con el fin de organizar la información y los datos obtenidos del proceso de investigación y del análisis, se conformaron tres capítulos. En cada uno de ellos, basándose en la teoría literaria y en los estudios sobre literatura de viajes, se reflexionó sobre los textos previamente señalados.

En el primer capítulo se fundamenta la literatura de viajes como un género de la literatura que acerca a la temporalidad de los hechos descritos o narrados. Así, teóricos como Luis Albuquerque-García y Ana María Moya Pellitero, entre otros, 
brindan los conceptos relativos a la literatura de viajes y construcción del paisaje. En este aspecto interesa destacar en los textos de estos autores que visitaron Centroamérica, la configuración y percepción que formularon sobre Honduras.

En el segundo capítulo se desarrolla el estudio del paisaje urbano que corresponde específicamente a la imagen y el retrato que se realiza de diversas ciudades de Honduras, ya que eran núcleos poblacionales importantes dada su ubicación, pero su desarrollo urbanístico, social y económico era aún insuficiente. Se resalta, además, la configuración que adquiere la ciudad en el marco de la significación para sus pobladores. Algunas de las ciudades que se describen son: Santa Rosa de Copán, Amapala, San Lorenzo, Pespire, Comayagua y Tegucigalpa. En muchas de ellas se señalan algunas de las construcciones urbanas más comunes como parques, calles, iglesias; se complementa lo anterior con las referencias sobre aspectos particulares de los lugares y referencias a los habitantes y sus condiciones sociales.

Finalmente, en el tercer capítulo, el paisaje natural de Honduras es exaltado por medio de descripciones que señalan las bondades y dificultades del territorio y sus recursos naturales; se mencionan los ríos, montañas y la vegetación, sobre los cuales abundan las referencias que expresan la conformación de estos espacios. Es bajo la mirada y narración por parte del autor-viajero que se identifica al paisaje como parte del constructo literario.

\section{MÉTODOS Y TÉCNICAS}

Para el desarrollo de esta investigación se ha empleado el Enfoque Cualitativo el cual permitió describir los rasgos y características del desarrollo temático tratado en la Literatura de Viajes y en la reseña realizada sobre la Construcción del paisaje, todo lo anterior condensado en un estudio Descriptivo. Con el método de Literatura Comparada se buscó señalar las características, elementos y análisis de los principales aspectos presentados por los autores y determinar puntos de encuentro, al igual que los aspectos divergentes entre ellos. Como herramienta de trabajo la Literatura Comparada ha facilitado el comentario y crítica de la obra literaria y verla como un objeto de estudio en su mayor extensión.

Se han escogidos textos corresponden a finales del siglo XIX y principios del XX: "In 
and out of Central America and other sketches and studies of travel", "Mexico and Central America A geographical reader" y "Beyond the Mexique Bay" de Frank Vincent, Harry Franck y Aldous Huxley respectivamente. Cabe destacar que los libros estudiados están en el idioma inglés -lengua en que fueron publicados- y es pertinente rescatar y difundir el contenido literario por su valor histórico y cultural. Igualmente señalamos que se ha realizado una traducción libre de los textos del inglés al español para su estudio.

Por medio de la investigación documental se partió del texto escrito para la realización de los análisis respectivos, además de verificar los datos, referencias históricas y geográficas que se encuentran a lo largo de la lectura de los libros. Después de realizar una recolección de la información, se buscaron libros de autores nacionales y extranjeros para conformar una amplia bibliografía teórico-crítica e histórica.

Aproximaciones a la literatura de viajes y la construcción del paisaje

Pocos estudios ofrecen un panorama crítico sobre la literatura de viajes, por eso una de las principales preocupaciones de esta investigación es indagar en la construcción del paisaje en la literatura de viajes en Honduras, para lo cual se estudiaron textos literarios que pertenecen a finales del siglo XIX y principios del XX.

Frank Vincent (1890) en su obra In and out of Central America and other sketches and studies of travel, relata su viaje por Centroamérica, el cual inició en Costa Rica y posteriormente siguió por Nicaragua, Honduras, El Salvador y Guatemala. Recorrió principalmente la costa del Pacífico en cada uno de los países, alternando el viaje entre el mar y la tierra. En su visita a Honduras recorrió la zona sur y central, deteniéndose en lugares como Amapala, San Lorenzo, Pespire, Sabana Grande y Tegucigalpa.

Harry Franck (1927) en su libro Mexico and Central America A geographical reader, dice que "un libro de viaje debe ser primero ante todo auténtico", Franck inicia su viaje en México, se dirige al sur y recorre cada uno de los países de Centroamérica hasta llegar a Panamá. En uno de los capítulos dedicado a esta tierra denominado En las profundidades de Honduras, describe su viaje por el llamado "camino real", cruzando por Santa Rosa de Copán, Comayagua, Tegucigalpa y Amapala.

Beyond the Mexique Bay, escrito en 1934 por Aldous Huxley, narra el viaje de este 
autor durante el cual recorre Barbados, Trinidad, Jamaica, Honduras Británica, Guatemala y Honduras; en este último país únicamente permaneció en Copán.

El paisaje dentro de la literatura ha sido uno de los motivos descriptivos más comunes para muchos autores. ¿En qué momento el paisaje se convierte en un objeto artístico? En la misma medida en que se permite una idealización, el goce y placer estético de los elementos naturales y urbanos presentados. El paisaje por sí mismo carece de este valor artístico, pues es el autor literario quien se lo infunde para cumplir ciertos propósitos estéticos. Tal representación se encuentra de igual manera en la pintura, siendo principalmente la interpretación del paisaje lo que evoca el placer artístico o estético que se ha recreado sobre él.

Una primera aproximación a los relatos de viaje la encontramos en Luis Albuquerque-García, quien señala la intencionalidad de este tipo de literatura:

El género (de los relatos de viaje) consiste en un discurso factual que se modula con motivo del viaje (con sus correspondientes marcas de itinerario, cronología y lugares) y cuya narración queda subordinada a la intención descriptiva, que dota al género de una cierta dosis de realismo. Suele adoptar la primera persona (a veces, la tercera), que nos remite siempre a la figura del autor como testigo de los hechos y aparece acompañada de ciertas figuras literarias que, no siendo exclusivas del género, sí al menos lo determinan... las marcas de paratextualidad (como correlato de la modalidad factual) y de intertextualidad son propias, aunque lógicamente tampoco exclusivas de estos relatos de viajes (2011, p. 33).

La orografía del país caracterizada por cordilleras y montañas provoca en el viajero admiración y sorpresa, de modo que no solo logra retratar de forma física la superficie terrestre, sino que interioriza en la vida dentro del país. Así, se observa que Harry Franck hace una breve descripción que remarca la irregularidad del territorio nacional, haciendo énfasis en las cadenas de montañas:

A excepción de una estrecha franja de pantanos en ambas costas, Honduras consiste en una serie de mesetas elevadas y filas de montañas. La cordillera o fila principal de montañas corre de noroeste a sureste y va en paralelo a unos cincuenta kilómetros de la costa del Pacífico... a diferencia de Guatemala, no tiene volcanes activos y no hay lagos. (1927, p. 200).

Aparte de esta breve descripción, la comparación entre Honduras y Guatemala sugiere algunas diferencias geográficas, destaca la orientación noroeste y sureste 
que siguen las cadenas de montañas y la posición paralela a la costa del Pacífico hondureño, a lo cual añade la no presencia de volcanes y lagos, aunque como bien es conocido, el principal lago de Honduras es el de Yojoa, que se encuentra en el norte del país.

Otro aspecto interesante es la reflexión que provoca en Franck la palabra Honduras, que corresponde al nombre del país; sobre este trata de definir su significado, así que consideró el predominio del territorio montañoso y el apoyo de datos históricos importantes para puntualizar lo siguiente:

Colón descubrió este país en 1502, en su cuarto viaje al Nuevo Mundo. Lo llamó Honduras, que en español significa "grandes profundidades ", debido a la dificultad de conseguir el anclaje en las aguas profundas a lo largo de su costa atlántica. Pero, es una tierra de grandes profundidades de otra manera también, entre sus cordilleras hay inmensos valles que a veces parecen no tener fin (1927, p. 201).

Si bien es cierto que la profundidad de las aguas como significado original fue nombrado por Cristóbal Colón, en este caso Franck describe también a las cadenas de montañas y vastos valles que hay en el país. Tanto Colón como Franck acuñan el término con una referencia distinta, pero dirigida hacia un mismo señalamiento: son un indicativo de la proporción, extensión y dificultad de recorrer este territorio, ya sea por mar o tierra.

\section{Descripción del paisaje urbano hondureño}

La ciudad convertida en paisaje es una consideración permitida por el valor simbólico que esta es capaz de absorber y transmitir, la ciudad como espacio vivo que puede transformarse y multiplicarse. Sobre esto, Ana María Moya Pellitero explica que:

La ciudad es contenedora de memoria individual y colectiva, como también de deseo y conexiones imaginarias. El entorno urbano bajo circunstancias históricas y culturales específicas se transforma en un espacio fenomenológico, con un significado estético, poético, intelectual, filosófico, percibido y representado, es decir, transformado en paisaje (2011, p. 25).

Harry Franck y Frank Vincent describen algunos de los pueblos y ciudades en los que pernoctaron durante su estadía en el territorio hondureño. Detallan de manera singular los elementos y características que más llamaron su atención. A continuación presentamos algunas descripciones de las principales ciudades de Honduras, según dichos autores. 
Amapala ha sido uno de los puertos más importantes de la zona sur del país, para su acceso es necesario emplear algún medio de transporte marítimo, pues se encuentra ubicado en la Isla del Tigre. Vincent destaca algunos de los rasgos notables de la isla, como las pequeñas colinas, la playa y el follaje que lo rodea: "El pueblo, que es muy pequeño, está llena de gente en medio de colinas empinadas y va precedida de una bonita playa de arena amarilla. El golfo, la playa amarilla, las murallas blancas y las montañas de exuberante vegetación crean un hermoso cuadro" (1890, p. 68). Finaliza esta descripción del lugar de forma casi paradisíaca, enfatizando el encanto de la belleza natural y señala como el pequeño pueblo sobresale en la isla.

En San Lorenzo, puerto y ciudad que se encuentra en la zona costera del Pacífico, según el viajero Vincent se destaca la magnificencia de la naturaleza y en su descripción parte del recorrido realizado desde la Isla del Tigre hasta llegar a las cercanías del lugar: "Remando por la orilla de la Isla del Tigre, la cual se conoce por ser una masa de rocas de lava, ahora encontramos una bonita playa de arena suave, pronto llegamos más allá de la tierra y hay una buena brisa, entonces, nos empujó rápidamente hacia el norte y hacia San Lorenzo" (1890, p. 72).

Esperando encontrar grandes ciudades, San Lorenzo era pequeña y pobre, por eso Vincent relata de esta manera su impresión: "Unas chozas pequeñas y miserables estaban en el barrio iy esto era San Lorenzo! Era plana y pantanosa y llena de mosquitos, jejenes, y pulgas. Los miserables habitantes sufrían de fiebre" (1890, $p$. 72). Empleando un tono admirativo, fue grande su sorpresa ante lo que había encontrado dentro del poblado: unas pocas chozas, mosquitos, jejenes y pulgas.

Al igual que en la mayoría de los pueblos de Honduras, el predominio del estilo arquitectónico colonial se refleja en la construcción urbana. Junto a la plaza o parque central se ubicaban los edificios de carácter político, religioso y económico más importantes. Un buen ejemplo de ello es la referencia que Frank Vincent ofrece de Pespire: "Pespire es un pequeño pueblo agrupado alrededor de una plaza que tiene una iglesia de regular tamaño con una cúpula blanca" (1890, p. 75). La iglesia generalmente ocupaba un lugar central dentro del espacio urbano, los habitantes vivían cerca y otros en los alrededores, de esta manera se marcaba la expansión de las ciudades o pueblos.

Señalándolo como un pueblo de tamaño considerable, Harry Franck inicia su viaje en Santa Rosa de Copán, en el occidente del país. Destaca la altitud en cuanto a la ubicación del pueblo y sus construcciones de una forma muy breve. Así lo señala en 
su libro: "La primera ciudad importante de Honduras que vi fue Santa Rosa. Se ubica a cuatro mil pies sobre el nivel del mar, hay un fino escenario sobre ella, el lugar parecía muy bonito a lo lejos con su iglesia blanca por encima de las casas pequeñas" (1927, p. 212). Para obtener una mejor vista, según lo relatado, se ubicó en un espacio desde el cual divisó el pueblo y comparó el tamaño de la iglesia con respecto a las casas cercanas y de techos bajos.

La llegada de Franck a Comayagua coincidió con la finalización del año. Comayagua ya había dejado de ser la capital de Honduras, pero aún poseía un fuerte poder económico, político, social y religioso. Este autor relata así su visita: "Cerca de la puesta del sol en el último día del año vine a Comayagua, es la segunda "ciudad" más grande de Honduras y antiguamente fue capital" (1927, p. 217). Tegucigalpa se convirtió en la capital de Honduras en 1880 y Comayagua es hasta el momento una de las ciudades principales del país.

El punto culminante del viaje de Vincent y Franck fue el arribo a Tegucigalpa, capital del país, cuya actividad minera constituyó por muchos años un recurso valioso para la economía local y nacional, la cual se dio por terminada con el cierre de las minas. El hecho de denominar a Tegucigalpa como "Ciudad de cerros de plata", se refiere al valor histórico y económico que se suscitó en la ciudad. Franck describe su llegada a la capital de esta manera: "A la mañana siguiente, justo al amanecer tengo a la vista mi objetivo, Tegucigalpa, la "Ciudad de los Cerros de Plata". Cuando entré en la Plaza Central, me di cuenta de que ya habían pasado quince días en el camino" (1927, p. 218-219). Tal como lo señala Franck, el viaje fue largo y difícil dadas las condiciones de transporte en el interior del país y las propias del territorio. Tardó quince días en llegar a la capital.

Pese a la concentración de diversos entes en la ciudad, esta conservaba aún cierta tranquilidad en comparación con otras ciudades cosmopolitas, tal situación causó admiración en Franck; al realizar una referencia sobre la ciudad dice: "Con sus 40.000 habitantes, la capital es realmente la única ciudad importante en el país, sin embargo, no es un lugar muy ajetreado" (1927, p. 219). Un sitio de interés para Franck fue el cerro El Picacho, porque desde allí se obtiene una de las mejores vistas panorámicas de la ciudad, de esta manera divisó Tegucigalpa: "Desde El Picacho, una larga cadena de montañas encierran por encima a Tegucigalpa, desde allí uno obtiene una buena vista de la ciudad" (1927, p. 221).

Aldous Huxley ofrece descripciones de la ciudad maya de Copán y relata su 
experiencia en las travesías por este lugar en el occidente del país. Son notables las variadas referencias correspondientes a la arquitectura y el arte que son parte de la naturaleza misma de estas construcciones mayas, así como el apego fiel a la representación de lo que encontró en ellas. A diferencia de otras ciudades de Honduras, Copán se encontraba deshabitada, siendo sus edificaciones los testigos mudos de la civilización maya.

En una primera descripción sobre Copán, la imagen que Huxley presenta es poco precisa debido a la maleza y destrucción natural que había recibido la ciudad con el transcurrir de los años, es así que desde un plano general, menciona que las paredes y piedras se encontraban caídas en los patios: "Copán, por ejemplo, tiene unos montículos cubiertos de árboles, una pared aquí y allá, algunos montones de piedras caídas, todos son los restos del gran complejo de pirámides, plataformas, de pared y terrazas, patios hundidos, que una vez ocuparon el sitio" (1934, p. 205-206).

Huxley describió todo aquello que observó, lo cual se relaciona directamente con lo que dice Luis Alburquerque sobre este hecho: "Si la narración consiste en relatar con palabras los sucesos que los seres llevan a cabo, la descripción, por el contrario, trata de 'pintar' con palabras, de manera que el receptor pueda ver mentalmente la realidad descrita. Así la descripción se suele reunir en tres fases: observación, reflexión y expresión adecuada" (2006, p. 79). Las descripciones de Huxley son precisas al retratar elementos particulares de Copán y la cultura maya.

Las estelas en Copán son un registro histórico de los principales sucesos de la vida maya, ya que por medio de los jeroglíficos se conocen estos datos. Por esta razón Huxley comenta sobre las estelas que observó y fotografió en Copán, prestando un interés especial en las paredes talladas de los templos y estelas, además de las figuras antropomorfas plasmadas por lo mayas y relacionadas con su cosmogonía:

Las estelas no son los únicos monumentos de Copán. Luchando entre las ruinas, encontramos una riqueza asombrosa de piedras talladas. Aquí había un gran cráneo cúbico con deslumbrantes cuencas en los ojos, sus dientes profundos en la hierba y la maleza; aquí, en la base de una pared rota, un friso de pequeñas calaveras en bajo relieve; aquí el famoso altar con su friso de sacerdotes-astrónomos fantásticamente adornadas en conferencia cientíica; aquí, tallada en círculo, la cabeza de un gigante, grotescamente con la boca abierta; aquí un par de estatuas rotas, pero aún con vida violentamente. (1934, p. 207).

Sin duda, este viajero quedó cautivado y maravillado de todo aquello que observó en 
las esculturas y monumentos, de modo que añade lo siguiente: "Los mejores ejemplares de escultura en los alrededores están en Copán. No vi nada comparable en gracia, sutileza artística, en expresividad emocional..." (Huxley, 1934, p. 207) La impresión visual causó un efecto de admiración, belleza y sorpresa en Huxley, en su escrito se percibe el descubrimiento de un mundo mítico, diferente y nuevo, una cultura que llamó totalmente su atención e interés.

\section{Recorrido por el paisaje natural de Honduras}

En esta descripción que se realiza del paisaje natural de Honduras, se observa a la naturaleza en su mayor esplendor, sin ninguna interferencia de la mano humana. Las referencia sobre la belleza encontrada en determinados parajes, indican que los autores viajeros demostraron una sensibilidad estética ante la riqueza de la naturaleza y es por medio del texto literario que este se refleja. Entre otros, se señalan los ríos, montañas y la vegetación, como parte de los motivos que predominan en estas descripciones.

\section{Ríos}

Las vías de tránsito terrestre están relacionadas a la ubicación de algunos ríos por donde se debe cruzar durante el viaje, pero también a la cercanía de las poblaciones que necesitan del agua para sobrevivir. Las descripciones que los autores viajeros comparten, señalan datos que indican la extensión y caudal de algunos ríos 0 simplemente presentan su descripción. Vincent realizó un cuadro sobre el río Moramulco que se encuentra al lado del camino y cercano a la villa de San Antonio de Flores, rodeado de bosque con abundancia de pájaros de colores y mariposas, inclusive, señala las rocas resbaladizas que sobre él se extienden: "En los bosques abundaban pájaros de muchos colores, en el camino y en el río, mariposas brillantes. El pueblo es miserable, San Antonio de Flores, estaba a nuestra izquierda, y el río Moramulco mostró su cauce lleno de rocas y piedras resbaladizas" (1890, p. 75).

Siguiendo a Vincent, llega a la comunidad de La Venta, no sin antes mencionar al río Nacaome, el cual atravesó en varias ocasiones; de él destaca su forma quebradiza y ondulante, señalando que en sus orillas se encuentran rocas de lava y guijarros:

Cerca de La Venta seguimos por el valle del río Nacaome. Cruzamos este río varias veces y lo encontramos de 50-300 pies de ancho. Actualmente es quebradizo y rápido. Su costa es de piedras volcánicas grandes y pequeñas. (1890, p. 75). 
Al mencionar al río Grande o Choluteca, Vincent indica que este nace en el Golfo de Fonseca y se extiende hasta llegar a Tegucigalpa:

Muchos ríos pequeños y un gran río -el Río Choluteca- alimentan al golfo. Por sobre el río Choluteca (llamado Río Grande por el nacimiento de sus aguas) se encuentra la capital hondureña, Tegucigalpa. El río es largo y tortuoso, pero navegable a poca distancia de su boca $(1890$, p. 67$)$.

\section{Montañas}

Durante el día se realizaban los recorridos a pie o con un animal de carga para avanzar hacia el lugar de destino, además de aprovechar la luz natural y conocer ampliamente el territorio. Tras recorrer una serie de montañas, Franck remarca la densidad de la vegetación en uno de los valles y de cómo esa noche se hospedó en una modesta casa hecha de varas y techo de paja:

El viaje comenzó con una dura caminata en la tarde por las colinas secas. Crucé cuatro montañas y pasé la primera noche en un estrecho valle con densa vegetación. La casa del hombre que me llevó estaba hecha de palos a manera de formar cuatro paredes, con techo de paja (1927, p. 204).

La hamaca servía de descanso especialmente durante la noche, pues debían buscar donde alojarse en algún lugar del camino y no necesariamente encontraban un hotel u hospedaje para ello, sino tal vez una casa de habitación o simplemente acomodarse en el bosque. Esta descripción también se refiere al frío de las montañas y a los peligros ante los animales salvajes que merodeaban:

Mi hamaca era de red y las noches eran frías en la montaña, a menudo eran demasiado frías como para dormir. No siempre era posible encontrar una casa al caer la noche y varias veces yo dormí bajo los árboles, pero sin saber si algún animal salvaje podría atacarme. (1927, p. 205).

En este texto de Frank se puede apreciar el placer de beber agua fresca de las montañas, el encanto de las caminatas a lo largo de las cordilleras, las vistas que son posibles de admirar a medida que se avanza, las cadenas de montañas en el horizonte y la soledad que existe en los caminos:

Al menos teníamos a menudo el placer de beber de un arroyo de montaña, agua limpia 
y fría y debo admitir que en ocasiones los senderos de Honduras te pueden dar la mejor caminata en el mundo. ¿Qué podría ser más agradable que vagar a lo largo de un camino de montaña cubierto de hierba, con magníficas vistas del bosque a cada lado, o por en medio de los propios bosques, después del azul de las montañas ver que se extienden hasta el horizonte? Al mismo tiempo, por varias millas no ver ningún ser humano (1927, p. 210).

\section{CONCLUSIONES}

En los textos de Aldous Huxley, Harry Franck y Frank Vincent se pueden reconocer los principales rasgos de la construcción del paisaje en Honduras, la cual coincide principalmente con las zonas geográficas en que se divide la nación: las zonas norte, central y sur; pero cada una está diferenciada y permite profundizar en un tipo específico de vegetación, flora y fauna, elementos geográficos y clima.

Los diversos señalamientos encontrados en estos autores indican que hay una cantidad innumerable de espacios con riqueza histórica, natural y cultural, pero que el país no se había desarrollado en otras áreas como las infraestructuras terrestres y marítimas, turismo, bienestar social.

En cuanto al ambiente urbano, se destaca el estilo arquitectónico de herencia colonial que se contrapone con las necesidades de construcción de edificaciones y vías modernas, la conformación de la ciudad por sus habitantes y los elementos simbólicos de las ciudades (parques, iglesias) que ahora forman parte del patrimonio cultural e histórico.

Sobre el paisaje natural ha quedado remarcado que Honduras posee una amplia belleza natural que se refleja a lo largo del territorio y que además en la conformación del país (costas, ríos, montañas) es de un valor incalculable. En esa época todavía la acción humana no permitía el daño de la naturaleza, la contaminación y sequía de las fuentes de agua, el mal manejo de los desechos sólidos, deforestación, tráfico de madera y animales, entre otros.

Sobre la importancia de esta investigación, se ha permitido destacar elementos literarios y de la construcción del paisaje hondureño que los libros ilustran a través del relato de viaje. Es así que, la UNAH al apoyar estas iniciativas en el campo de la investigación literaria reconoce la importancia que requiere el estudio minucioso y 
científico que se desarrolla desde disciplinas como las Humanidades, Ciencias Sociales y específicamente en la Literatura, donde lastimosamente a veces no se brindan los espacios y oportunidades necesarias. Además, la divulgación de este tipo de estudios permite indagar en nuestra identidad nacional, el reconocimiento de rasgos culturales, la historia, la lengua, la cultura y la literatura del país.

Finalmente, los autores viajeros demostraron su amor por la naturaleza, su sensibilidad ante el paisaje mismo; como en todo viaje, el deseo de explorar y conocer también se convirtió en una de sus motivaciones para proseguir en su periplo por el territorio hondureño. Los textos que fueron analizados quedan como evidencia de la apreciación artística de estos viajeros y autores literarios de finales del siglo XIX y principios del XX.

\section{BIBLIOGRAFÍA}

Alburquerque-García, Luis. (2011). El relato de viajes: hitos y formas en la evolución del género. Revista CSIC, (145). España.

Franck, Harry A. (1927). Mexico and Central America A Geographical Reader. New York: F. A. Owen Publishing Company.

Huxley, Aldous. (1934). Beyond the Mexique Bay. London: Chato \& Windus.

Moya Pellitero, Ana María. (2011). La percepción del paisaje urbano. Madrid: Editorial Biblioteca Nueva.

Vincent, Frank. (1890). In and out of Central America and other sketches and studies of travel. New York: D. Appleton and Company. 